\title{
Medicine, healing, and ways of knowing in the colonial Caribbean
}

\author{
Medicina, cura e modos de conhecimento no Caribe colonial
}

\author{
Adam Warren \\ Professor, Department of History/University of Washington. \\ Seattle - Washington - USA \\ awarren2@u.washington.edu
}

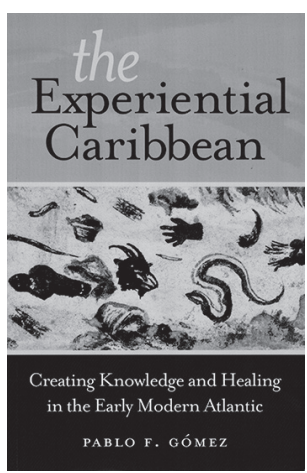

GÓMEZ, Pablo F. The experiential Caribbean: creating knowledge and healing in the early modern Atlantic. Chapel Hill, NC: University of North Carolina Press. 2017. 291p.
$\mathrm{P}$ ablo Gómez's The experiential Caribbean: creating knowledge and healing in the early modern Atlantic (2017) challenges us to think in new ways about how we conceptualize the production and circulation of knowledge about bodies, health, disease, and healing in the sixteenth- and seventeenth-century Atlantic World. It is a sweeping, ambitious, and provocative analysis of the various practices and beliefs black ritual specialists and healers in the Caribbean employed under Spanish colonial rule to create truths about the world around them and address the forms of sickness and health they encountered. Central to Gómez's intervention in the fields of intellectual history and the history of medicine is his argument that such healers developed their own "ways of knowing" based on experience, on forms of sensing and perceiving, and on traditions brought to the Caribbean from multiple locations, which guided how they could act on the world and on the bodies of patients through ritual. Beliefs about bodies, health, disease, and healing in

the Caribbean, he suggests, cannot and should not be understood solely in terms either of the degree to which they resembled or deviated from a Galenic/Hippocratic model brought there from Europe, or the degree to which they followed epistemological shifts within Europe itself during the sixteenth and seventeenth centuries. Indeed, the use of such a Eurocentric framework, Gómez argues, obscures and distorts more than it reveals about knowledge creation and healing in the Caribbean. European ideas certainly comingled with African and indigenous ones, but rather than trying to measure or trace them as intact and easily identifiable derivatives of a European belief system, we should understand them as being incorporated and merged with other beliefs to create something entirely new. Indeed, by reconstructing how ordinary people sought to make sense of epidemics and disease, Gómez posits an epistemological revolution in the Caribbean that coincided temporally with, but did not resemble in content and form, revolutions in science and medicine in sixteenth- and seventeenth-century Europe. 
The importance of The experiential Caribbean should not be underestimated. The argument outlined above constitutes a call for intellectual historians and historians of science and medicine of the colonial period to rethink how they conceptualize knowledge production and the movement of knowledge within the Atlantic World. At one level, Gómez argues rightly and convincingly for the decentering of Europe within that framework. At another level, however, he makes a major contribution by bringing in ordinary historical actors (in this case, black Caribbean ritual specialists and healers) as key protagonists in a history of the development of new epistemologies in the Caribbean. Rather than the study of natural philosophers, theologians, and other learned figures who had access to books and education, intellectual history here becomes the study of everyday people and the ways they grappled with and learned from both the landscapes they inhabited and the people with whom they interacted. Likewise, medical and scientific knowledge production becomes characterized by processes in which the boundaries separating trained and licensed practitioners from their popular counterparts prove irrelevant. Instead, the vibrant intellectual life of the Caribbean is made visible through Gómez's masterful use of cultural historical and ethnohistorical methods to shed light on how systems and practices of knowledge creation worked on the ground and circulated. In many respects, The experiential Caribbean models how ethnohistorical methods can be employed on a scale that is uncommon in existing scholarship, much of which focuses on narrowly defined regions or even single communities, in order to make bold claims about how we should understand the early modern period. Furthermore, it builds on the ways other scholars of indigenous and African communities have approached the history of medicine by focusing less on the identification of "authentic" bounded cultural systems and more on the movement, appropriation, and deployment of ideas. The result is a nuanced reconstruction of how historical actors developed their own ways of sensing, perceiving, and knowing the world around them in the Caribbean.

Beyond these interventions aimed at intellectual historians and historians of science and medicine, Gómez's work makes contributions to colonial Latin American history in several ways. Perhaps first and foremost, it provides an invaluable case study of society, religion, medicine, and healing in the early- and mid-colonial Caribbean, which the author fruitfully compares with existing studies of Peru and New Spain, the more developed centers of empire during these centuries. Through his sophisticated analysis of archival materials and his deep regional expertise and engagement of scholarship, Gómez demonstrates that the Caribbean constituted a different kind of space for the production of ideas about bodies, health, disease, and healing due to its deep and immediate connections to the Atlantic economy and the slave trade. In his analysis of cities like Cartagena de Indias and Havana during this period prior to the rise of the plantation economy, he describes a larger social milieu where the particular structures, practices, and patterns of colonization meant that no single medical model or belief system dominated others, and where boundaries separating different kinds of populations from one another were far from rigid. Recognizing in crucial ways the brutality and abuse that were daily features of colonial life, Gómez convincingly shows that black ritual specialists and healers nevertheless engaged the world around them creatively and challenged the power and authority of others. They drew, moreover, on 
many different traditions and adapted them according to perceptions of the natural world around them. The result is a more fluid culture of medical practice than what scholars like myself have found in Lima or Mexico City, one that tends to bear more similarities to the medical practices and cultures of healing James Sweet and others have examined in colonial Brazil and the larger Portuguese Empire. Furthermore, as a case study it can be placed fruitfully into dialog with studies of other peripheral regions of the Spanish Empire.

In addition to its contributions to our understanding of the place of healers and ritual specialists in Caribbean societies, Gómez's work also provides an important depiction of broader society and culture in the Caribbean during the sixteenth and seventeenth centuries. It therefore constitutes a valuable intervention in Caribbean social and cultural history. Of particular note, his analysis of Inquisition records moves beyond concerns about the rhetoric of demonology and the cultural filters shaping actions by regulators of the faith to uncover a fascinating world of rituals and beliefs widely shared across society. Gómez, moreover, juxtaposes Inquisition cases with an impressive variety of other kinds of sources - including visual sources, catalogs of materia medica, and travelers' writings, among others - in order to extend his claims and delineate larger patterns and sets of practices that were widely accepted. His work will without doubt be of interest to scholars of religion in colonial Latin America as well as historians of the Atlantic World, historians of slavery, historians of African diaspora populations, ethnohistorians, and historians of science and medicine. It is, in short, an excellent work of scholarship that is deserving of a wide audience.

\section{REFERENCES}

GÓMEZ, Pablo F.

The experiential Caribbean: creating knowledge

and healing in the early modern Atlantic.

Chapel Hill, NC: University of North Carolina

Press. 2017. 